\title{
MARS: LOCAL STRUCTURE OF DUST STORMS
}

\section{G. I. BARENBLATT}

Institute of Mechanics of Moscow University, Moscow, U.S.S.R.

and

\section{G. S. GOLITSYN}

Institute of Atmospheric Physics, Academy of Sciences of the U.S.S.R., Moscow, U.S.S.R.

\begin{abstract}
A hydronamical theory describing the motion of the dusty flow including the effects of thermal stratification is presented. It is shown that the dust, while decreasing the intensity of turbulence in the flow, can accelerate the wind. Applied to Mars, the theory reveals that these effects may be important there in understanding the nature and the long duration of Martian dust storms.
\end{abstract}

